\title{
Automated nutrients analysis for buoys in sea-water and intercalibration
}

\section{Filippo Azzaro}

National Research Council, Institute for Marine and Coastal Environment, Detached Unit of Messina Spianata S. Raineri Messina, Italy

\section{Email address:}

filippo.azzaro@iamc.cnr.it

\section{To cite this article:}

Filippo Azzaro. Automated Nutrients Analysis for Buoys in Sea-Water and Intercalibration. International Journal of Environmental Monitoring and Analysis. Vol. 1, No. 6, 2013, pp. 315-322. doi: 10.11648/j.ijema.20130106.17

\begin{abstract}
The Nutrient Probe Analyser-4 (NPA-4) is an automatic chemical analyser for "in-situ" and continuous measurements, based on a new improvement of the exclusive analytical technology developed by Systea and named LFA (Loop Flow Analysis); LFA has permitted levels never reached before in analytical automation and in analyser miniaturisation. With NPA-4 probes, it is possible to analyse directly in the water up to four parameters with the same instrument, using a particular configuration of LFA technology, which allows the sequential analysis of more than one analytical method in a single analytical reactor (30 minutes for a complete 4 parameters cycle). It has been conceived to execute ammonium, nitrate-nitrite, nitrite and orthophosphate analysis at low concentration in sea water samples. The hermetic closed Loop provides full protection against background interference, a basic requirement for stable trace analysis. At the start of a cycle the loop is washed and filled with sample. The sample colour is measured for compensation. Small amounts of concentrated reagents are added and mixed with high intensity. The intensity of the colour of the reaction product is measured one or two colorimetric dual beam with silicon detector, depending on requested methods. The standard wet chemistries for nutrients analysis used in NPA-4 are the ones recommended by international standard The statistical test show that the results of automated and manual analyses agree for all the examined parameters. Precision of all four analyses is $\leq 3 \% \mathrm{RSD}$. The Limit of detection of 5, 5, 2.5 and $2.5 \mu \mathrm{g} / \mathrm{L}$ were reported for $\mathrm{N}-\mathrm{NH}_{4}, \mathrm{~N}-\mathrm{NO}_{3}, \mathrm{~N}-\mathrm{NO}_{2}$ and $\mathrm{P}-\mathrm{PO}_{4}$, respectively. Multiparametric on line analyzer: it is possible to connect to a data logger with analogue and digital signals, in order to have on line simultaneous analysis of the sample. A typical application is on line analysis of seawater on an oceanographic research buoy (Max $-5 \mathrm{~m})$. It does not require any operator.
\end{abstract}

Keywords: Seawater, Ammonia, Nitrates, Nitrites, Orthophosphate, Colorimetric Techniques

\section{Introduction}

Continuous monitoring of a highly dynamic system such as coastal waters requires frequent sampling at a precise place in order to catch short-term events which might have a strong impact on the coastal ecosystem, such as exceptional phytoplankton blooms or change caused by storms.

The lack of monitoring systems that provide continuous observations of the marine environment, especially concerning chemical species like nutrients in the coastal areas and shelf seas of Europe, is a serious hindrance. Instruments for in-situ dissolved nutrient analyses are needed by oceanographers. In-situ measurement techniques have many advantages, like avoiding the use of storage bottles to be shipped to land-based laboratories, reducing the risk of sample contamination. In any case, additional and collateral sampling can be performed when special phenomena are identified.

Automated procedures for the analysis of water sample for nutrients are preferable manual methods when large number of samples and mainly on an oceanographic research buoy. In the course of the last thirty-five years an ever increasing number of automatic tools for Colorimetric analysis, principally using "Continuous Flow Analysis" [1,2] and "Flow Injection Analysis" [3-7] have been devised. The analysers of this kind, employed for the determination of phosphorus and nitrogen salts, generally have detection limitations, insufficient to satisfy the analytical demands concerning sea-water, generally characterized by poor nutrients.

The need to have in the automatic monitoring operations the real-time determination of some chemical parameters (such as nutrients) in environments at risk, has made the realization of a automatic chemical analyser suitable for on buoy installation. 
The Nutrient Probe Analyser (MultiParametric) is an automatic chemical analyser for measurement of seawater (Fig. 1), based on analytical technology developed by Systea (italian company) and named LFA (Loop Flow Analysis).

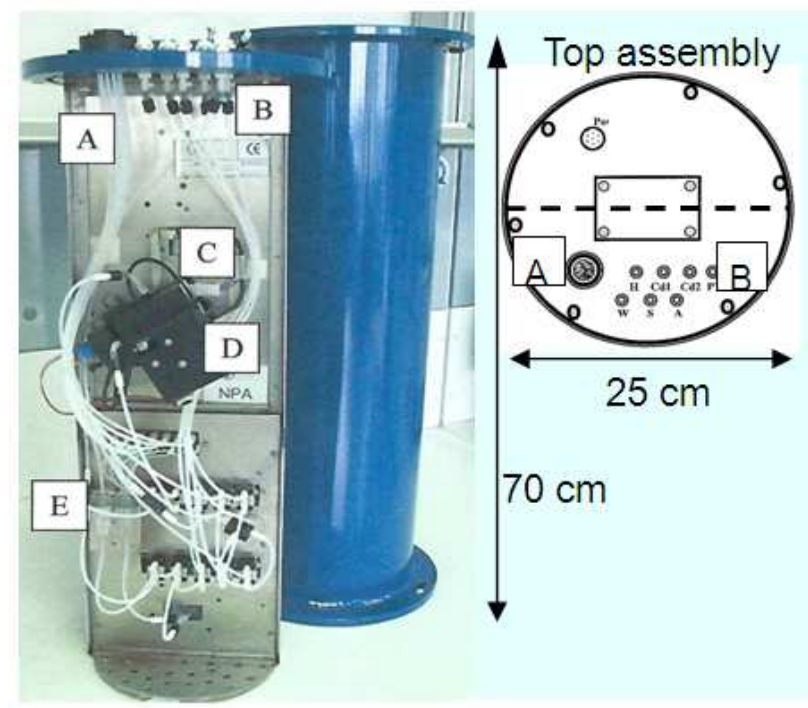

Figure 1. Nutrient Probe Analyser-4; (A) Reagents tube, (B) Inlet outlet tube, (C) Heating bath connector, (D) Colorimeter, (E) Hydraulic manifold.

LFA has permitted levels never reached before in analytical automation and in analyser miniaturization [8-11]. All the steps of a wet-chemical colorimetric analysis method are carried out in an analysis cycle sequentially. The Loop Flow Reactor (LFR) components are sequentially connected to form a Loop, that can be opened (sampling position) or closed (analysis position) by means of $2 \times 3$ ways valve. The hermetic closed Loop provides full protection against background interference, a basic requirement for stable trace analysis. At the beginning of a cycle the loop is washed and filled with a sample. The sample colour is measured for compensation. Small amounts of concentrated reagents are added and vigorously mixed.

\section{Materials and Methods}

\subsection{Instrument Description}

The Nutrient Probe Analyser (NPA)-4 is designed to perform sequential measurement of four common nutrient parameters, namely dissolved orthophosphate, ammonia, nitrite and nitrate, which are normally measured during field studies. It is composed by an aluminium cylinders diameter $250 \mathrm{~mm}$, height $700 \mathrm{~mm}$ ) submersible up to $5 \mathrm{~m}$ depth. NPA-4 technical data are reported in Table 1.

\subsection{Analytical Cycle}

A NPA-4 is able to run sequentially one or more analytical cycles (chemistries) under the control of the local microprocessor.

The necessary steps for a complete single analytical cycle are the following:

1. Sample aspiration and introduction in analytical reactor.

2. Sample blank (deionized water) measurement and colorimeter zeroing (time T0).

3 . Reagents injection with the proper sequence and timing.

4. Sample and reagents mixing.

5. Heating if needed.

6. Optical density increase measurement with a double beam colorimeter (time T1).

7. End point measurement storing in non volatile RAM for successive remote and local readings.

8. Concentration value automatic calculation, based on the correlation with internal calibration factor.

Table 1. Nutrient Probe Analyser technical data

\begin{tabular}{|c|c|}
\hline Measured parameters: & $\mathrm{NH}_{3}, \mathrm{PO}_{4}, \mathrm{NO}_{3}+\mathrm{NO}_{2}, \mathrm{NO}_{2}$ \\
\hline Detectors: & $\begin{array}{l}\text { two colorimetric dual beam with silicon detector, } \\
\text { depending on requested methods ( } 660 \text { and } 525 \mathrm{~nm} \text { ) }\end{array}$ \\
\hline Type of analysis: & sequential batch \\
\hline Analysis interval: & programmable \\
\hline Measuring time: & 30 minutes for a complete 4 parameters cycle \\
\hline $\begin{array}{l}\text { Number of } \\
\text { parameters: }\end{array}$ & up to 4 \\
\hline Maximum in-situ depth: & $5 \mathrm{~m}(2 \mathrm{~m}$ suggested $)$ \\
\hline Body material: & Aluminium \\
\hline Operating temperature: & $8^{\circ}-27^{\circ} \mathrm{C}$ \\
\hline $\begin{array}{l}\text { Hydraulic } \\
\text { connections: }\end{array}$ & std. $3.2 \times 1.6 \mathrm{~mm}$ \\
\hline Waste: & directly discharged in water; optional waste bag available on request \\
\hline Reagent expiring: & 3 to 10 weeks, depending on the method and water temperature \\
\hline Reagent compartment cooling: & Refrigerated by surrounding water; Peltier refrigeration available on request \\
\hline Autonomy: & up to one month, depending on measurement interval time \\
\hline
\end{tabular}




\begin{tabular}{ll}
\hline Hardware: & industrial PC-104 CPU, externally programmable by serial communication port \\
Data output: & RS 232 serial port; RS 422 or RS 485 available on request \\
NPA control functions: & a) PC: Control Software Windows based, connection on serial port \\
External connections: & b) External keyboard: IP65 with 16 keys keyboard and 2x16 LCD display, internal connection, do not use on field. \\
Power supply: & 6-pole submergible cable for serial data communication and power supply; parallel connector for the control panel \\
Power absorption: & power \\
Weight: & $4 \mathrm{~W}$ in stand by, $10 \mathrm{~W}$ during analysis (mean), $20 \mathrm{~W}$ peak absorption \\
Dimensions: & $25 \mathrm{Kg}$ without reagents (in air) \\
\hline
\end{tabular}

\subsection{Calibration Cycle}

Calibration with working standard:

The mixed working standard is normally placed inside the NPA reagents container; it will be used as it is, instead of sample, during calibration cycles. For each method, the calibration cycle analyse a standard to calculate the calibration factor

\subsection{Analytical Cycle Description}

\subsubsection{LFR Reactor - Main Components}

A simple LFA monoparametric analytical reactor includes several devices (mechanical, hydraulics, optics) sequentially interconnected to form a ring defined LOOP FLOW REACTOR (LFR). A standard LFR hydraulic schematic diagram is shown in the previous drawing (Fig. 2); components shown are enough to run up to four chemistries, with the possibility to select two different wavelength.

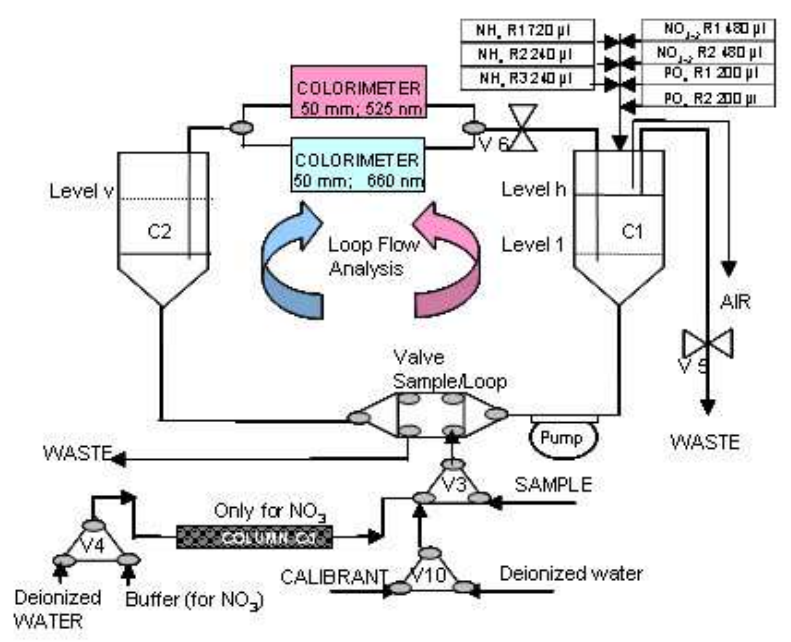

Figure 2. Hydraulic schematic diagram for determination of ammonia, nitrate +nitite, nitrite and orthophosphate. $V$ (valves); $C$ (chambers).

Valves S/L allows to open the LFR to pump sample, standard or blank solution in (SAMPLE position) or to keep the LFR closed in LOOP, to allows mixing of reaction product. The cylinder $\mathrm{C} 1$ allows the injection of the reagents and the calibrant (only in case of calibration using a stock calibrant see 2.3 Calibration cycle) in the LFR, and contributes to create a strong turbulence inside the circuit, in order to speed up the mixing phase.
The valve V6, when activated, interrupts the LFR hydraulic connection and contributes to the vacuum production inside $\mathrm{C} 1$. The pump $\mathrm{P}$ is a single tube peristaltic pump that can be activated in direct or reverse mode. The valve V4 are activated only when a sample reduction is needed before analysis (i.e. for $\mathrm{NO}_{3}-\mathrm{NO}_{2}$ reduction). The valves $\mathrm{V} 10$ and V3 are used to select Sample, Diluent and Calibrant.

The cylinder $\mathrm{C} 2$ is normally filled with air and contributes to the vacuum production in $\mathrm{C}$, containing temporarily the volume of liquid pumped out from $\mathrm{C} 1$ by the pump $\mathrm{P}$.

\subsection{Sampling}

With valves $\mathrm{S} / \mathrm{L}$ and V3 on, the pump $\mathrm{P}$ is activated in direct mode; the sample is pumped in the cylinder $\mathrm{C} 1$, and once reached the level $\mathrm{Lh}$ it goes up on the tube, passes through V6, through the colorimeters flow cells, and than reaches $\mathrm{C} 2$ and flows out to the waste through the opposite section of the valves $\mathrm{S} / \mathrm{L}$. After an appropriate sampling time, the cylinder $\mathrm{C} 1$ is filled up to the level Lh by closing V6 and opening V5.

All the LFR components, including the flow cell, are now filled with sample; the system can read and store the Sample Blank value that will be subtracted from the final OD of the reaction product.

\subsection{Analysis}

Following operation are valid for Sample analysis, Reagent Blank and Calibration

To start the analysis valves $\mathrm{S} / \mathrm{L}$ are switched off to close LFR in LOOP.

\subsubsection{Reagent Injection}

To inject reagents into the LFR the valve V6 is closed and the pump $\mathrm{P}$ is started in reverse mode until the liquid in $\mathrm{C} 1$ will reach the level Ll.

The volume of liquid between $\mathrm{Lh}$ and $\mathrm{Ll}$ has been moved in $\mathrm{C} 2$ where has reached the level Lv; the strong vacuum produced with this operation in $\mathrm{C} 1$ will allows to suck the reagents, with a thin and fast flow-out, activating for a precise time (proportional to the volume), the microvalves V1-7 connected to the reagents containers.

\subsubsection{Pressure Compensation}

Opening the valve V6 will restore the original levels in $\mathrm{C} 1$ and $\mathrm{C} 2$. 
To compensate the overpressure, after reagents injection, valves $\mathrm{S} / \mathrm{L}$ are switched on for few seconds allowing discharge of excess of liquid contained in the circuit.

\subsubsection{Mixing}

Valves $\mathrm{S} / \mathrm{L}$ are positioned again in LOOP, the pump $\mathrm{P}$ is activated in direct mode, to allow a fast mixing of sample and the reagents.

The special position of the IN and OUT tubes inside C1 will contribute to produce a strong turbulence thus allowing a fast mixing and the start of the chemical reaction.

\subsubsection{Reaction and $O D$ Reading}

The reaction takes place in all points of the reactor and therefore in the colorimeter flow cell, thus allowing the monitoring of the reaction from time 0 (reagents injection) to the end point.

If methods require heating, to speed up the colour development (i.e. for $\mathrm{NH}_{4}, \mathrm{PO}_{4}$ ) only the colorimeter flow cell will be heated at the requested temperature.

At the reaction end point, measured OD is stored.

\subsubsection{Calculations}

Reagent Blank OD: stored and used to calculate the calibration factor.

Calibrant OD: stored and used to calculate the calibration factor.

Sample OD: stored together Sample Blank OD and used to calculate Sample concentration.

Sample concentration $=($ Sample OD - Sample Blank OD - Reagent Blank OD) x Calibration factor.

\subsubsection{Wash}

Valves $\mathrm{S} / \mathrm{L}$ are switched on, all other valves are off, to allows pumping of diluent (usually deionized water). Pump $P$ is activated in direct mode, water fill up LFR washing hydraulics.

After a proper washing time (about $1 \mathrm{~min}$ ) LFR, remains in stand by filled with distilled water ready for a new run.

\subsubsection{Analytical Procedure}

The NPA-4 nutrients probe was configured to measure the nutrient parameters $\left(\mathrm{NH}_{3}-\mathrm{N}, \mathrm{PO}_{4}-\mathrm{P}, \mathrm{NO}_{3}-\mathrm{N}, \mathrm{NO}_{2}-\mathrm{N}\right)$ in sea water using the analytical sequence and the standard wet chemical methods reported in [9] and those recommended by international standards $[12,13]$. The general analytical sequence and the procedures are summarized in Table 2.

\subsection{Determination of Ammonia in Seawater}

In this automated method, the ammonia ions present in the sample react with phenol and hypochlorite in an alkaline medium according to Bethelot's reaction; trisodium citrate and EDTA are added to the sample to avoid the precipitation of alkaline hydroxides, while nitroprusside acts as a catalyst. The indophenol blue is measured at $660 \mathrm{~nm}$.

\subsection{Determination of Nitrate+Nitrite and Nitrite}

In this automated method, the nitrate present in the sample is reduced to nitrite in a coppered cadmium column, in a buffered medium. The nitrites formed and the ones already present in the sample, react with sulphanilamide and $\mathrm{N}$-(1-naphtyl) ethylendiamine in acid medium to give a coloured diazonium salt, which is measured at $525 \mathrm{~nm}$.

\subsection{Determination of Phosphate in Seawater}

In this automated method, the orthophosphate present in the sample reacts with molybdate in an acid medium to form phosphomolybdate, and then with ascorbic acid to form molybdenum blue, whose intensity is measured at $660 \mathrm{~nm}$. The antymonium catalyzes the reaction.

\section{Results and Analyses}

The colorimetric methods examined have different reaction rates reaching the maximum value of optical density for ammonia after 60 minutes, nitrate-nitrite after 8 minutes and phosphate after 25 minutes [14]. The difference between the value of optical density read at time $\mathrm{T} 1$ and that recorded at time T0 is proportional to the nutrient concentration under examination. The NPA-4 is a sensitive instrument, also able to detect variations in optical density in the order of a tenth of milli-adsorption units (mAU); it is not therefore necessary for the colorimetric dose to wait for the complete development of the color (Fig. 3). The value of the time T1 usually results from the compromise between the need for the maximum development of color and the number of analysed samples per unit of time.

Table 2. Analytical protocol for the ammonia, nitrate+nitrite, nitrate and phosphate determinations.

\begin{tabular}{llll}
\hline Name & Phosphate & Ammonia & Nitrate+Nitrite \\
\hline Filtration & Yes & & Nitrite \\
Sampling & $90 \mathrm{sec}$ & & Sulfanilamide \\
Sample blank reading & Yes (Deionized water) & Citrate alk, Hypochlorite alk & Naphthyl-ethylenediamine \\
First reagent & Acid molybdate & Phen.alk + Dichloroisocyanuric & \\
Second reagent & Ascorbic acid & & 525 nm \\
Mixing conditions & yes & & ---- \\
Colorimeter & $660 \mathrm{~nm}$ & $45^{\circ} \mathrm{C}$ & \\
Temperature condit. & $25^{\circ} \mathrm{C}$ & & - \\
Light path & $50 \mathrm{~mm}$ & & \\
\hline
\end{tabular}




\begin{tabular}{|c|c|c|c|c|}
\hline Name & Phosphate & Ammonia & Nitrate+Nitrite & Nitrite \\
\hline Range LOD-LOL & $2,5-500 \mu \mathrm{g} / \mathrm{L}$ & $5-200 \mu \mathrm{g} / \mathrm{L}$ & $5-500 \mu \mathrm{g} / \mathrm{L}$ & $2,5-200 \mu \mathrm{g} / \mathrm{L}$ \\
\hline Kind of measurem & \multicolumn{4}{|l|}{ End point } \\
\hline Sample blank & \multicolumn{4}{|c|}{ Automatic zeroing at the end of sampling } \\
\hline Calibration & \multicolumn{4}{|c|}{ Automatic preparation of the working calibrant } \\
\hline Calib. ratio mode & \multicolumn{4}{|l|}{ factor } \\
\hline Time analys & 5 minutes & 9 minutes & 7 minutes & 5 minutes \\
\hline Vol. reag. $(\mu l)$ & 960 & 1200 & 400 & 400 \\
\hline Wash cycle & \multicolumn{4}{|l|}{$50 \mathrm{sec}$} \\
\hline
\end{tabular}

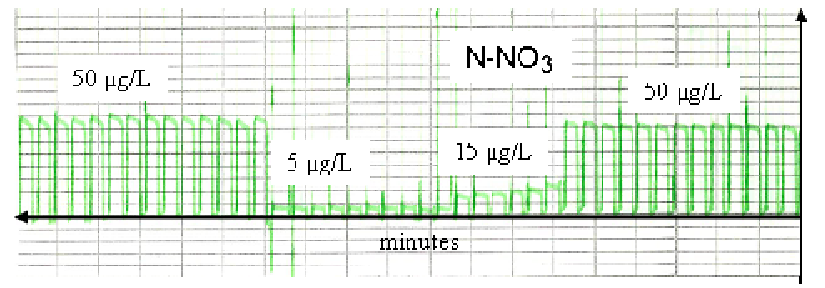

Figure 3. Standard recorder trances-nitrates product of reaction in 7 minutes

An important aspect of the system concerns the possibility sample blank measurement and colorimeter zeroing, measuring the optical density immediately after the addition of reagents and the aspiration in the cell, making the approximation that at T0 the colorimetric reaction has not yet occurred. With this stratagem it is possible to correct the value of the optical density, compensating for variations linked to the instability of the lamp, salinity or turbidity of the matrix
[15], without resorting to dual ray systems.

The general analytical sequence and the procedures for the four considered parameters in sea water are summarized in Table 2.

The calibration, for each method, may be done either with a reading of a standard located in the reaction chamber or the factor may be set from a series of standard readings at various concentrations, aspirated as samples.

\subsection{Accuracy and Precision}

The precision of the analysis was evaluated by analysing a series of standard solutions $(15,10,7,5$ and $2.5 \mu \mathrm{g} / \mathrm{L}) 15$ times for all the methods and calculating the relative standard deviation \% (RSD) of the measurements (Table 3 ).

The analysis precision proves satisfactory with a $\%$ RSD average of 2,96 for the ammonia, 2,99 for the nitrates, 2,24 for the nitrites, and 2,49 for the phosphates.

Table 3. Acuracy and precision (RSD- relative standard deviation) for each method.

\begin{tabular}{|c|c|c|c|c|c|c|}
\hline \multirow[t]{2}{*}{ Nutrient Species } & & \multicolumn{5}{|c|}{ Known Concentration $(\mu \mathrm{g} / \mathrm{L})$} \\
\hline & & 15 & 10 & 7.5 & 5 & 2.5 \\
\hline \multirow[t]{3}{*}{ Ammonia } & Mean Concentrat. & 14.98 & 9.78 & 7.45 & 4.89 & 2.10 \\
\hline & Stand. Deviation & 0.15 & 0.17 & 0.12 & 0.16 & 0.13 \\
\hline & $\%$ RSD & 1.00 & 1.73 & 1.61 & 4.29 & 6.19 \\
\hline \multirow[t]{3}{*}{ Nitrate } & Mean Concentrat. & 15.06 & 9.89 & 7.56 & 5.06 & 2.46 \\
\hline & Stand. Deviation & 0.32 & 0.21 & 0.19 & 0.19 & 0.11 \\
\hline & $\%$ RSD & 2.12 & 2.12 & 2.51 & 3.75 & 4.47 \\
\hline \multirow[t]{3}{*}{ Nitrite } & Mean Concentrat & 15.00 & 9.99 & 7.51 & 4.98 & 2.49 \\
\hline & Stand. Deviation & 0.1 & 0.14 & 0.16 & 0.15 & 0.10 \\
\hline & $\%$ RSD & 0.66 & 1.4 & 2.13 & 3.01 & 4.01 \\
\hline \multirow[t]{3}{*}{ Phosphate } & Mean Concentrat & 14.99 & 10.02 & 7.49 & 5.06 & 2.44 \\
\hline & Stand. Deviation & 0.10 & 0.18 & 0.16 & 0.19 & 0.19 \\
\hline & $\%$ RSD & 0.67 & 1.80 & 2.14 & 3.75 & 4.09 \\
\hline
\end{tabular}

\subsection{Limit Range}

Limit of detection (LOD) and limit of linearity (LOL), were calculated using approved validation methods and statistically based estimation and the results shown in Table 2.

\subsection{Carryover Studies}

The effects of carry-over or washout error which may be present when solutions at highly varied concentrations are sequentially analysed have been evaluated.

The Broughton [16] carryover percentage (K) was calculated according to the equation: carryover $(\%)=[(\mathrm{L} 1-$ L3)/(H3 - L3)] x 100. Three consecutive samples with high (H) concentrations (ex $200 \mu \mathrm{g} / \mathrm{L}$ of $\mathrm{NH}_{4}$ ) were measured, followed by three with low (L) concentrations (ex $10 \mu \mathrm{g} / \mathrm{L}$ of $\mathrm{NH}_{4}$ ), and this sequence was repeated five times. 
All the measures you make and for the four analysed parameters a carry-over coefficient superior than $0,4 \%$ has not been highlighted.

\subsection{Comparison of Manual and Automated Chemical Analyses}

Intercalibration of manual and automated procedures is necessary to detect systematic bias in either method, and to ensure that data from automated analyses are compatible with data from manual analyses (Fig. 4).

Stock Standards $(15,10,7,5,2.5 \mu \mathrm{g} / \mathrm{L}$ prepared in low-nutrient seawater) were used for test the agreement between the Nutrient Probe Analyser (lightpath $50 \mathrm{~mm}$ ) and the spectrophotometer determinations Varian Mod. Cary 50, (lightpath $50 \mathrm{~mm}$ ).
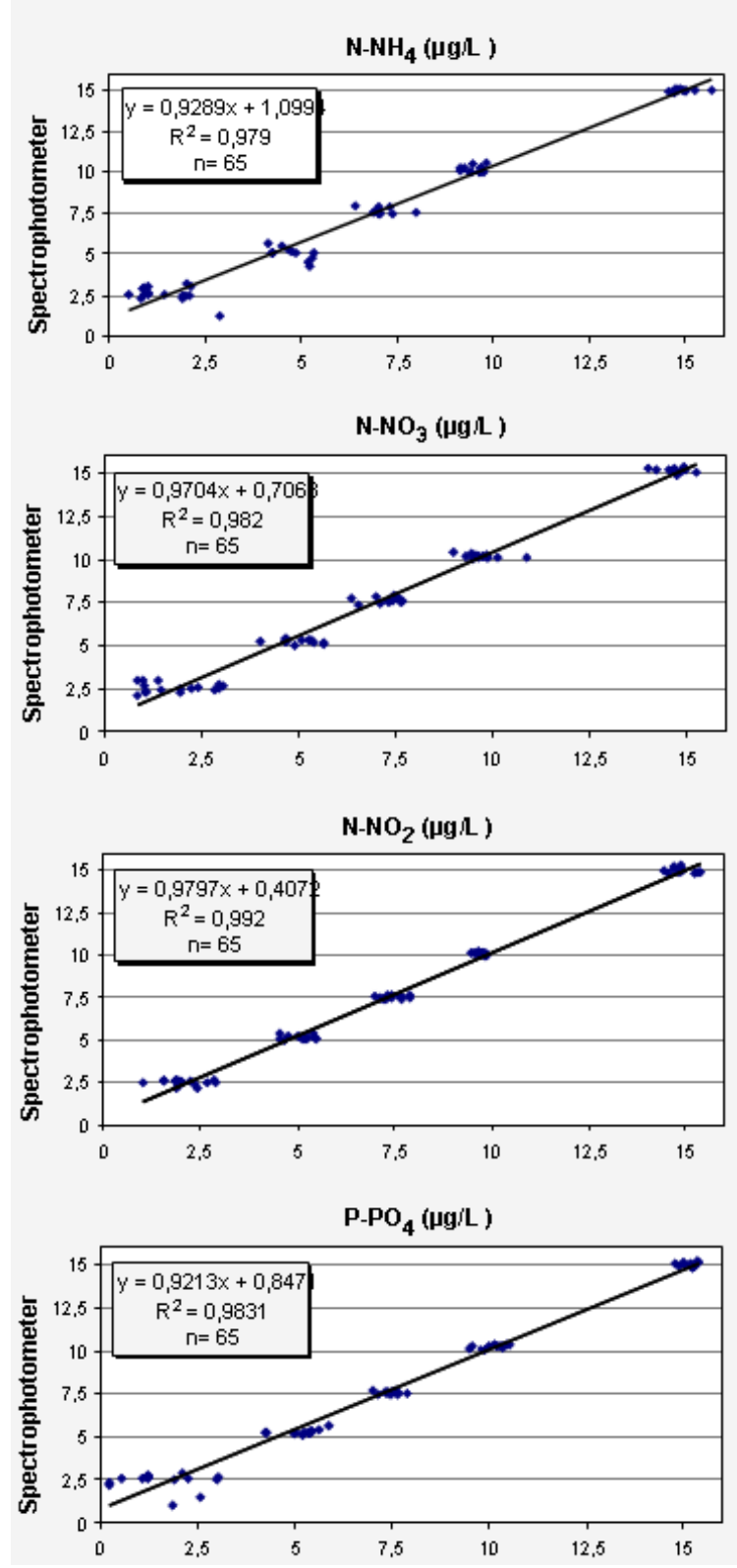

Figure 4. Linear regression analysis relationship between Nutrient Probe Analyser-4 and manual determinations (Spectrophotometer) of ammonia, nitrate + nitite, nitrite and orthophosphate

\subsection{Correlation Coefficient}

Results indicate good agreement of the two methods with a correlation coefficient $\mathrm{R}^{2}=0,979$ for $\mathrm{NH}_{4}, 0,982$ for $\mathrm{NO}_{3}$, 0,992 for $\mathrm{NO}_{2}$ and 0,983 for $\mathrm{PO}_{4}$, calculated on $\mathrm{n}=65$ (Fig. 4). The Limit of detection (LODs) for methods nitrite and orthophosphate is of $2.5 \mu \mathrm{g} / \mathrm{L}$, while for ammonium and nitrate it is $5 \mu \mathrm{g} / \mathrm{L}$, considering that the readings below that value were not perfectly repeatable as they were for other concentrations.

If the values of $2.5 \mu \mathrm{g} / \mathrm{L}$ were removed then the correlation coefficient would be $\mathrm{R} 2=0,98$ for $\mathrm{NH}_{4}$ and 0,985 for $\mathrm{NO}_{3}$, calculated on $\mathrm{n}=54$.

\subsection{Instrumental Drift}

The evaluation of repeatability was tested through measurement two standards solution in seawater containing 15 $\mu \mathrm{g} / \mathrm{L}$ (orthophosphate and nitrites), $30 \mu \mathrm{g} / \mathrm{L}$ (ammonia and nitrates) was analyzed for 15 days.

The solutions were prepared in a 5 liters container and shaken with a magnetic shaker. The results, shown in Figure 5 do not reveal any instrumental drift.

Anomalous values were recorded occasionally during the various experiments, probably due to air bubbles in the circuit that created errors in reading the sample; these determinations were not included in the elaborations.

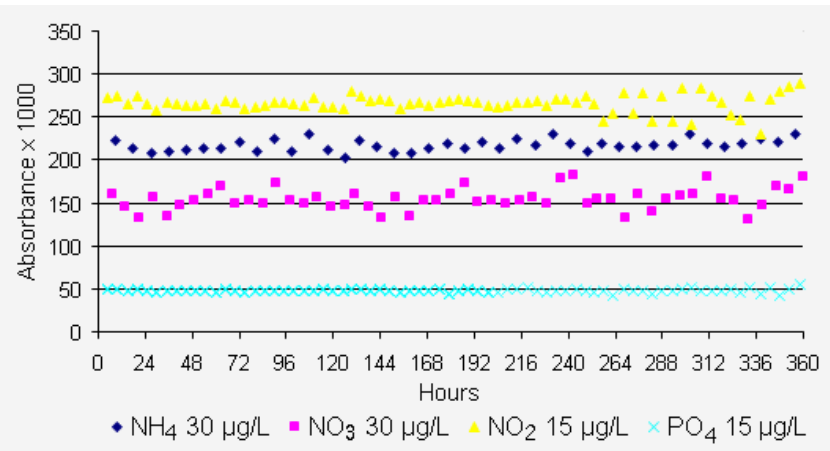

Figure 5. Linear regression analysis relationship between Nutrient Probe Analyser-4 and manual determinations (Spectrophotometer) of ammonia, nitrate+nitite, nitrite and orthophosphate

\subsection{NPA-4 on Automatic Coastal Platform}

The study was performed over 11 months (form February to December) in the context of Cluster 10 - SAM Programme (Advanced Monitoring Systems) funded by the Italian national Ministry for Scientific Research. A test of implementation has been done at IAMC-CNR Messina with Nutrients Probe Analyzer and it was later installed in the Gulf of Milazzo (Sicily) in the costal platform station starting from August 13 ${ }^{\text {th }}$, (Fig. 6). This station was measuring nutrients, salinity, seawater and air temperature, fluorescence, turbidity, dissolved oxygen, PAR, and wind speed [17, 18]. The NPA-4 nutrients in-situ probe was configured to measure automatically and unattended the nutrient parameters $\left(\mathrm{NH}_{4}-\mathrm{N}, \mathrm{PO}_{4}-\mathrm{P}, \mathrm{NO}_{3}-\mathrm{N}, \mathrm{NO}_{2}-\mathrm{N}\right)$ in sea water using the analytical sequence and the standard wet chemical methods 
reported in this paper. The sampling frequency chosen was adapted to the amount of reagents and standards that were filling the flexible bags $(500 \mathrm{ml})$. A about 3-month field test was planned with a 6 hours sampling frequency to run cycles of four nutrients measurements. Online working standards were respectively of $100 \mu \mathrm{g} / \mathrm{L}$ for ammonia, $50 \mu \mathrm{g} / \mathrm{L}$ for phosphates, $20 \mu \mathrm{g} / \mathrm{L}$ for nitrites and $100 \mu \mathrm{g} / \mathrm{L}$ for nitrates. Regular in situ calibration checks were made using on-board concentrated standard automatically diluted by the probe before the measurement.

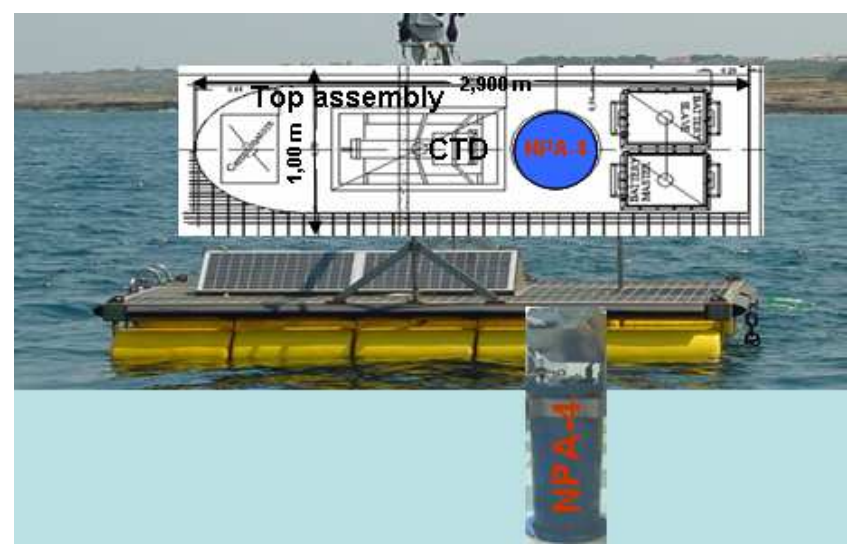

Figure 6. Nutrient Probe Analyser-4 installed on oceanographic platform (buoy).

During the sample intake, the sample is filtered through a $10 \mu \mathrm{m}$ metal filter screen and during cleaning cycles the filtering unit is flushed several times with compressed air to prevent any back clogging of the filter.

Change of reagents and calibration standards were done every 10 days. Two analyzers were used making a rotation every 20 days during maintenance operations, in order to ensure a complete clean up and recalibration.

The results, presented in Fig. 7 shows the concentration nutrient trend provided by the probe from August $13^{\text {th }}$ to November $11^{\text {th }}$. Very low values were obtained, typical from this period of the season and of the oligotrophic water on area Gulf of Milazzo (Sicily). The good stability of the $\mathrm{PO}_{4}$ (range 2.4-18.5 $\mu \mathrm{g} / \mathrm{L}$, median $9.2 \mu \mathrm{g} / \mathrm{L}$ ) and $\mathrm{NO}_{2}$ (range $0.2-7.8 \mu \mathrm{g} / \mathrm{L}$, median $2.04 \mu \mathrm{g} / \mathrm{L}$ ) concentrations in the Gulf is highlighted.

Due to wind-driven upwelling (three periods) between September $16^{\text {th }}$ and October $16^{\text {th }}$ an increase in salinity, $\mathrm{NH}_{3}$ and $\mathrm{NO}_{3}$ concentration was observed (up to about $30 \mu \mathrm{g} / \mathrm{L}$ for ammonia, with a median of $6.21 \mu \mathrm{g} / \mathrm{L}$ and up to about $23 \mu \mathrm{g} / \mathrm{L}$ for nitrates, with a median of $11,96 \mu \mathrm{g} / \mathrm{L}$ ).

\section{Conclusions}

The results obtained suggest that the Nutrient Probe Analyser is reliable for the automatic performing of chemical analyses of ammonium, nitrate, nitrite and phosphates in sea water. The correlation with traditional methods is optimal, considering also the other positive experiments such as the repeatability of data and the absence of drift. In fact, the cleaning of the loops and the colorimeter is a very important feature for the sea water analysis.
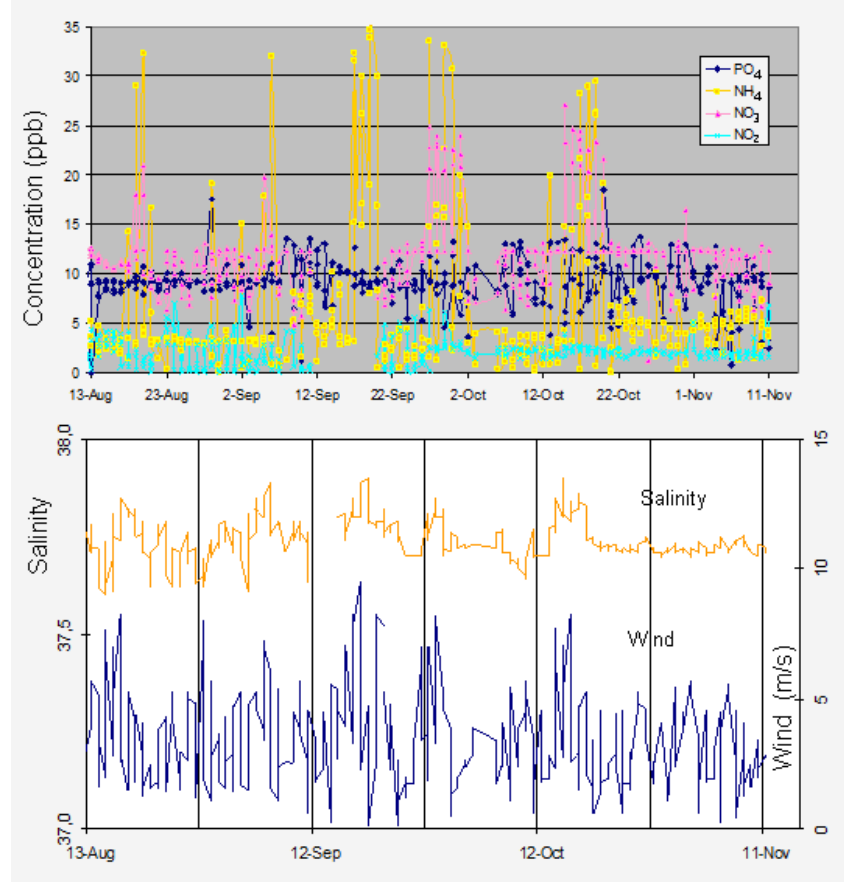

Figure 7. Platform data: automatic hourly series of meteoceanographic parameters (windspeed, salinity) and $N$-, P-nutrients at the surface, every 6 hours.

Indeed, in flow instrumentation the drift is a limiting factor especially for the orthophosphate and ammonium analysis.

The compactness and the robustness, together with the low reagents consumption, allow the system to be easy used directly for environmental monitoring and research activities. Another important result was the deployment of the Nutrient Probe Analyser on in situ conditions in the costal platform station. It has been successfully performed with the demonstration of the capability of such system to work on an automated mode with a good accuracy. The probe deployed was loaded with reagents for 2 weeks autonomy and it carried sufficient quantity of standards and DI water to analyze four nutrient parameters continuously at $6 \mathrm{~h}$ intervals during the reported period.

In conclusion, the Nutrient Probe Analyser meet the required characteristics, both for repeatability, accuracy and precision, with universally recognised analytical methods. Analysis of nutrients on an equipped coastal buoy is the typical application of Nutrient Probe Analyser that can run a fully automated analysis of nutrients in sea-water.

\section{Acknowledgements}

The study was carried out within MURST (Italian Ministry for University and Scientific Research) Cluster 10-SAM (Systems Advanced Monitoring) Project. The author is grateful to A. Marini for assistance with the analyses and A. Cosenza for help in providing with computer programs. 


\section{References}

[1] X.A. Alvarez-Salgado, F. Fraga, and. F.F. Pérez, Determination of nutrient salts by automatic methods both in seawater and brackish water: the phosphate blank. Mar. Chem., 1992, $39,311-319$.

[2] J. Barwell-Clarke, and F. Whitney,. Institute of ocean sciences nutrient methods and analysis. Can. Tech. Rep. Hydrogr. Ocean Sci. 1996, 182, vi - 43 pp

[3] Y. Hiray, N. Yoza, S. Ohashi, Flow injection analysis of inorganic ortho and poly-phosphate using ascorbic acid as reductant of molybdophosphate. Chem. Lett., 1980, 5, 499-502.

[4] C.B. Ranger, Flow Injection Analysis. Anal. Chem. 1981, 53, 20A.

[5] K.S. Johnson, R.L. Petty, Determination of nitrate and nitrite in seawater by flow injection analisis. Oceanogr. Limnol. 1983. $28,1260-1266$.

[6] S.M Oliveira., T.I. Marques Da Silva Lopes, I.V. Tóth, A.O. Santos Silva, Rangel, Determination of ammonium in marine waters using a gas diffusion multicommuted flow injection system with in-line prevention of metal hydroxides precipitation. J. Environ. Monit., 2009. 11, 228-234

[7] R. Vuillemin, D. Le Roux, P. Dorval, K. Bucas, J. P. Sudreau, M. Hamon, C. Le Gall, P M. Sarradin,. CHEMINI: A new in situ CHEmical MINIaturized analyzer Deep Sea Research Part I: Oceanographic Research Papers, 2009, 56, 1391-1399.

[8] F. Azzaro, E.. Crisafi, G. Magazzù, F. Oliva, A. Puglisi, Un nuovo fotometro automatico per la determinazione di nutrienti da boa Oceanografica. In: Atti "Workshop: Il monitoraggio automatico dell'inquinamento marino". Taranto, Italy. 1994., pp 213-226.

[9] F. Azzaro, M. Galletta,. Automatic colorimetric analyzer prototype for high frequency measurement of nutrients in seawater. Mar. Chem., 2006, 99, 191-198.

[10] P. Moscetta, L. Sanfilippo, E. Savino, P. Moscetta, R. Allabashi, A. Gunatilaka, Instrumentation for continuous monitoring in marine environments. OCEANS 2009, MTS/IEEE Biloxi - Marine Technology for Our Future: Global and Local Challenges, 26-29 Oct. 2009, Biloxi, USA

[11] R. Vuillemin, L. Sanfilippo, P. Moscetta, L. Zudaire, E. Carbones, E. Maria, C. Tricoire, L. Oriol, S. Blain, N. Le Bris, P. Lebaron, Continuous Nutrient automated monitoring on the Mediterranean Sea using in situ flow analyser. OCEANS 2009, MTS/IEEE Biloxi - Marine Technology for Our Future: Global and Local Challenges, 26-29 Oct. 2009, Biloxi, USA

[12] J.D.H. Strickland, T.R. Parsons, A practical handbook of seawate analysis: Bull. Fish. Res. Ed. Can. 1972, 167, 1-311.

[13] K. Grasshoff, "Methods of seawater analysis," with contributions by A. Almgreen, R.Dawson, M.Erhardt, S.H. Fonselius, B.Josefsson, F.Koroleff and K. Kremling, Verlag Chemie, Weinheim, 1976, 1-317.

[14] N. Cardellicchio, M. Luzzana, Messa a punto di un prototipo di analizzatore colorimetrico programmabile per la determinazione automatica dei nutrienti in acqua di mare. Atti del Seminario Tecnico Scientifico del Progetto Strategico "Monitoraggio automatico dell'Inquinamento Marino nel Mezzogiorno" Lecce Italy, 1993, pp 137-158.

[15] P.N. Froelich, M.F.Q. Pilson, Systematic absorbance errors with Technicon Autoanalyzer II colorimeters. Water Res., 1978, 12, 599-603.

[16] P.M.G. Broughton., A.H.. Gowenlock, J.J. McCormack, D.W. Neill, A revised scheme for the evaluation of automatic instruments for use in clinical chemistry. Ann. Clin. Biochem., $1974,11,207-218$.

[17] S. Friedhelm and K. Hans-Diethard, Water quality time-series data of the lower Brantas river, east Java, indonesia: results from an automated water quality monitoring station. Asian J. Water. Environ. Pollut., 2013, 10(1), pp. $55-72$.

[18] Blain, J. Guillou, P. Tréguer, P. Woerther, L. Delauney, E. follenfant, O. Gontier, M. Hamon, B. Leildé, A. Masson, C. Tartu, R. Vuillemin, "High Frequency Monitoring of Coastal Marine Environment using MAREL buoy", J. Environ. Monit., 2004, 6(6) 569-575, 